\title{
Failing The Final Exam In Equal Employment And Opportunity
}

\author{
Greg Tower, Curtin University of Technology, Perth, Australia \\ Julie Plummer, University of Western Australia, Perth, Australia \\ Brenda Ridgewell, Curtin University of Technology, Perth, Australia \\ Emily Goforth, Curtin University of Technology, Perth, Australia \\ Spence Tower, Ferris State University, Big Rapids Michigan, USA
}

\begin{abstract}
Anglo-American educational global leaders are failing the final exam for overall transparency of EEO activities with over $90 \%$ non-disclosure. Australian entities should be modeled as important communication exemplars.
\end{abstract}

Keywords: Equal employment opportunity, university, communication, annual report.

\section{POSITIONING THE RESEARCH}

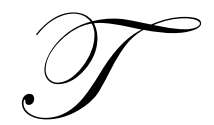

his is a study about communication--or the lack of it. Leaders are now far more willing to recognize the crucial importance of their people power. How organizations deal with their personnel is now considered a fundamental concern and a matter of their highest priority. Accordingly, this study examines the vastly important set of issues encompassing Equal Employment and Opportunity. It closely examines the communication of EEO activities to stakeholders external to the organization. A public sector exemplar is adopted with the sample frame used being the very best English-language-based universities in the world. A review of the key literature is first provided. This is followed by an outline of the research design, data set, descriptions of construct measures and analytical techniques. Finally, reflections on the findings are advanced.

Worland and Anderson (1991) examine the disclosure of human resource information by Australian top companies using two measures namely: 1) the proportion of the director's narrative report devoted to human resource issues; and 2) the proportion of paragraph contained in the report featuring identifiable employees as part of this subject. The specific human resource topics examined are current wage fixation issues, items arising from legislative change and topics with regards to change in direction of human resource management. Whilst slightly more than half of the companies acknowledged the contribution of employees to the company's operations, nearly forty percent of companies made no such statement and a majority of these did not refer to the employee's work contributions. Only a few companies reported on industrial disputation and human resource strategy. Worland and Anderson (1991) conclude the disclosure of human resource information is limited.

Research has also explored gender-based communication items via annual reports. For instance, Benschop and Meihuizen (2002) look at how representations of gender in texts, figures and photographs in Netherlands' corporate financial reports and how they contribute to the gendering of organizations. They apply a four-step score card: 1) to analyze each picture of people; 2) group the pictures into three categories; 3 ) obtain overview of weighted average score percentages within that category; 4) run logit regressions to find whether there is differences between the sexes. Their study argues that gender-based communication is done as a routine and ongoing accomplishment of the corporate identity. They state that stereotypical images are dominant and the representational practices reinforce the traditional gendered division of labor and conclude that financial reports have a masculine commutation that strengthen the masculine logic of accounting.

Bernardi et al. (2005) examine whether there are diversity differences between Fortune 500 corporations that provide/do not provide pictures of their boards. Their results show that there is a significance increase in the 
presence of ethnic minorities and females when pictures of board members are included in the annual reports. The authors suggest that a mandatory requirement of including pictures of board members in annual reports and regulatory filings would result in a larger presence for gender and race diversity on boards of directors.

Grosser and Moon (2005) focus on how gender equality in the workplace is incorporated into corporate social responsibility (CSR) reporting in the UK. Their study highlight the additional potential areas for the representation of women's voice as stakeholders in company practices, as employees, community members, consumers, suppliers and investors in CSR systems and processes.

Nichols et al. (1997) sought to determine whether gender differences exist in the interpretation of what is or is not considered as sexual harassment. Their findings show that male CPAs are less apt to find a man guilty of sexual harassment as compared to females CPAs. Yet, Kirkham (1997) and Hammond (1997) argue that the Nichols et. al. (1997) study failed to explore important gender issues which invade the accountant's professional practice especially in regard to the wider social dynamic. Kirkham further suggests that in order to understand the nature and extent of any relationship between sexual harassment and accounting, a consideration of non-gender accounting research is needed to focus on 'sexual behavior in accounting firms'. Kirkham (1997) states that non-gender focused accounting research needs to recognize the possible implication of intimidating sexual behaviors on research agendas and methods.

The above text provides a broad overview of some of the key EEO research studies conducted. The next section brings this into a sharper focus by reviewing the key literature of EEO-style communication in the higher education sector.

\section{EEO COMMUNICATION BY THE UNIVERSITY SECTOR}

Kastl and Kleiner (2001) note two key forms of discrimination and harassment in the university-setting namely: racial discrimination and sexual discrimination. The authors observe the difficulty of applying the diverse definitions of sexual harassment throughout the world. There are two categories that sexual harassment in the eye of the laws: 1) quid pro quo category - when someone with authority over the victim and 2) creating a hostile working or learning environment for harassment. Sexual harassment in academia usually involves difficulties between students (lead to hostile education environment) and/or professor to student type of sexual harassment (quid pro quo category). Meanwhile, racial discrimination in admission policies remains a major concern in the university environment. In an attempt to improve on equity issues, many lawmakers have promulgated statutes giving minority groups the opportunity to enter universities even though their qualification at point of admission may not be at par with other non-minority students. Additionally, affirmation action plans were enacted to encourage minorities to new heights through academic achievement. Universities have set up comprehensive policies on sexual and racial discrimination, implement workshops on policy implementation and evolved special programs on handling racist attitudes and racial discrimination. Some of these initiatives may be conducted as a strategy to protect the university from excessive litigation.

The literature also highlights the way that gender and race biases may impact on career path. Weisenfeld and Robinson-Backmon (2001) conduct a survey regarding perceptions of African-American accountants with respect to discrimination, career advancement curtailment and mentoring support. They then advance suggestions to the education institutions on ways to help the minorities to overcome such career progression obstacles. Key recommendations to help minority students prior to their working entry include the university providing internships, mentoring program and emphasizing the importance of oral and written communication skills. In addition, the respondents suggested the educational institutions conduct seminars on various topics such as diversity issues, handling discrimination, the transition from college to work, corporate politics and culture.

Sewell (1971) looked at inequality of opportunities in the higher education sector with respect to policy implications. He claims that opportunities for higher education are contingent on characteristics of social origin i.e. sex, socioeconomic origins, race and ethnic background. Daly (2005) sampled over 300 business students from public universities and notes differences between people of varying races and between males and females in the sources of influence that they attribute to their choice of college major. Jacobs (1996) analysis distinguishes access 
to higher education; college experiences and post college outcomes. His analysis reveals that women cope relatively well in the area of access, less in terms of college experiences and are particularly disadvantaged with respect to the outcome of schooling. As a result he suggests that access, process and outcomes should be examined separately in research on higher education.

Fitzgerald et. al. (1988) developed an instrument called Sexual Experiences Questionnaires (SEQ) which covers five general areas: gender harassment; seductive behavior; sexual bribery; sexual coercion and sexual assault. This instrument has been since employed by many researchers in the sexual harassment field. These studies have found that gender harassment and seductive behaviors are the most common situations experienced by women students and workers. Employed women had experienced seductive sexual approaches from their professors and coworkers. Direct sexual coercion such as bribery and intimidation appears much less widespread. The study concluded that sexual harassment is about the misuse of power, whether organizationally or institutionally, in a manner that construct a barrier to a woman's educational and occupational pursuits.

Stockdale and Vaux (1993) explore what type of personal experiences lead women and men to state that they had been "sexually harassed". Study participants were sampled from three groups at a large Midwestern USA university: undergraduate students, graduate students and staff (including civil service, administrative / professional, and faculty) using the Sexual Experience Questionnaires (SEQ). As predicted, experience of sexual seduction, sexual bribery / coercion or sexual imposition each increased the odds of acknowledgement. Contrary to prediction, the probability of acknowledging harassment was unrelated to gender or the form of harassment experienced.

Kelly and Parsons (2000) focused on the experiences of women in academia in a university that has a publicized policy and procedures regarding sexual harassment. Thirty percent of the staff, $22 \%$ of faculty, $20 \%$ of undergraduate students and $19 \%$ of graduate students reported having been sexually harassed while as employee (or student) at the university. Undergraduate women reported other students as perpetrators of sexual harassment, whereas graduate women most often reported male faculty as perpetrators. Ninety-one percent of the time the reported offenders were male, whereas $9 \%$ of the respondents reported a female perpetrator. Staff members are the most likely group of women to report having experienced offensive sexual behavior. Another important finding is that, despite the availability of policy / procedure at the university surveyed, women continue to prefer non-formal and non-assertive responses to sexual harassment.

With regards to gender discrimination in the university, Menges and Exum (1983) noted that before the 1980s, the proportion of women and minority faculty relative to all academics did not increase significantly. They summarize that the reasons are due to: small pool of potential and actual candidates; the ineffectiveness of affirmative action programs and problems faced by women and minorities during tenure and promotion review. Other possible reasons highlighted for the differential progress of women and minorities are: overt discrimination and negative decisions about renewal, promotion and tenure due to the lower perceptions of women's work contribution.

DiAugelli (1989) reviews studies on the issue of gays and lesbians, heterosexual and homophobia prior to the introduction of sexual orientation matter in the university policy at Penn State University. The Lesbian and Gay Student Alliance (LGSA) members used DiAugelli's 1987 study documented evidence to encourage the University to recognize the seriousness of these issues to their students. Consequently in May 1988, the University's policy defining sexual harassment of students was extended to include harassment based on sexual orientation. The authors argued that this was the beginning on Penn State's turnaround and the starting point in the empowerment process of lesbians and gay men on campus. Since then, lesbians and gay men were allowed to use facilities and were allocated funding like other students groups.

Todd and Bird (2000) conduct a case study analyzing the changes to the promotion policies and practices at the University of Western Australia (UWA). Their data is gathered from a wide range of university documents and records, and also from interviews from a sample of 30 women and men interviewees chosen to reflect a spread of faculties, length of service at UWA and current position. Their key finding was that changes in the UWA academic promotion practice have been vital in eliminating previous inequality in the promotion exercise; this is evidenced by significant improvement in the women's promotion rate. Some of the changes include: increase the pool of 
academics eligibility for promotion application; recognition of a fuller range of activities being undertaken by academics; increase transparency of the promotion process; greater support and guidance for applicants and the recognition of gender as an issue.

Suarez-Balcazar et al. (2003) argue the importance of studying race and ethnic discrimination incidents in college campuses stating it is crucial to understand the interplay of psychological and socio-environmental factors associated with experiences of differential treatment among college students, especially those from minority groups. They sampled 500 Caucasian and 495 other racial blends of students randomly selected from 5,272 population of students enrolled at a private Midwestern urban university. Their findings suggest that African American students experience, on average more incidents of differential treatment in college-related situations than their Hispanic, Asian and Caucasian counterparts. The authors also observe that minority students are more likely to socialize with students from their same race. Moreover, females rate the situations higher as compared to males for 'degree of offensiveness' and 'degree of discrimination'.

Overall, these above studies highlight a plethora of issues in regards to Equal Employment and Opportunities on college campuses throughout the world. These issues range broadly from sexual orientation to sexual gender discrimination, from racial and religious intolerance to discrimination against physical and mental disabilities. Clearly these EEO issues are of paramount importance to the university community. Accordingly, this study gathers and analyses data below to better access EEO communication levels for the elite universities in the economically powerful Anglo-American countries.

\section{RESEARCH DATA INSIGHTS ON EQUAL EMPLOYMENT OPPORTUNITY COMMUNICATION AND ACTIVITY}

This research builds upon the work of Tower, Plummer, Ridgewell, Goforth \& Tower (2008a; 2008b) to generate insights on EEO communication and activity. Using a global tertiary education data set, Tower et al (2008a) found that the overall transparency level of the world's most prestigious universities regarding their Knowledge Management (KM) activities was a paltry $26.5 \%$. Further analysis compares the 22 USA universities (with an even lower 22.5\%) to the other 28 global tertiary institutions (a statistically noticeable higher value of 29.6\%). Whereas, Tower et al (2008b) looked specifically at EEO issues; their data set was the population of Australian universities. They observed that universities from larger states with potentially more extensive EEO legislation discussed far more EEO details then their smaller brethren. They also noted the paucity of detail for 'Sexual Orientation' and 'Religion' categories (8-25\%) with somewhat more disclosure (30-40\%) for 'Gender', 'Disability' and 'Race' themes. Tower et al (2008b, p.10) conclude "Lack of transparency is thus a major concern with low levels of reporting for all key EEO categories. The tertiary education sector may well need to voluntarily put more emphasis on such key issues before pressure to generate legislated mandates mount".

In this study, equal employment and opportunity insights using the top 50 ranked English-language universities in the world as rated by The Times Higher Education Supplement (2007). This data set of the top English speaking universities ranks 22 USA universities in the top 50 sample along with 13 from the United Kingdom, eight from Australia, four from Canada and three from other countries (two from Singapore and one from New Zealand). Descriptive analysis finds that the universities have very low profit figures but financially are very strong with an average of over a billion dollars of total assets per institution and limited borrowing obligations.

EEO communication is measured as a metric percentage ranging from $0-100 \%$. This is labeled as an Equal Employment and Opportunity Disclosure Index (EEODI) and is constructed upward from 104 information points in the key sub-categories of sexual orientation, gender, religion, race and disabilities. The overall mean disclosure of items was seen in Australian institutions at 21.97\%, followed by the UK at 5.90\%, the U.S. at $5.30 \%$ and Canada, New Zealand and Singapore falling below $4 \%$ disclosure.

The findings highlight the level of EEO communication for these world's best universities is a disappointing 7.9\% (see Table 1 and Figure 1). Over 90\% of the comprehensive EEO issues are not disclosed by these global leaders. Figure 1 pinpoints the major statistical differences between the eight Australian universities in the top 50 list versus the other 42 Anglo-American institutions. The Australian entities have far higher disclosure levels for every key category except 'Sexual Orientation' wherein both groups disclose less than 4\%. No other 
university-country grouping has over $15 \%$ on any key category. Interestingly, the overall Australian university EEO communication levels are over four times higher than all other countries in the sample frame.

Figure 1: EEO Disclosure Levels: Australia as Compared to Other Anglo-American Universities

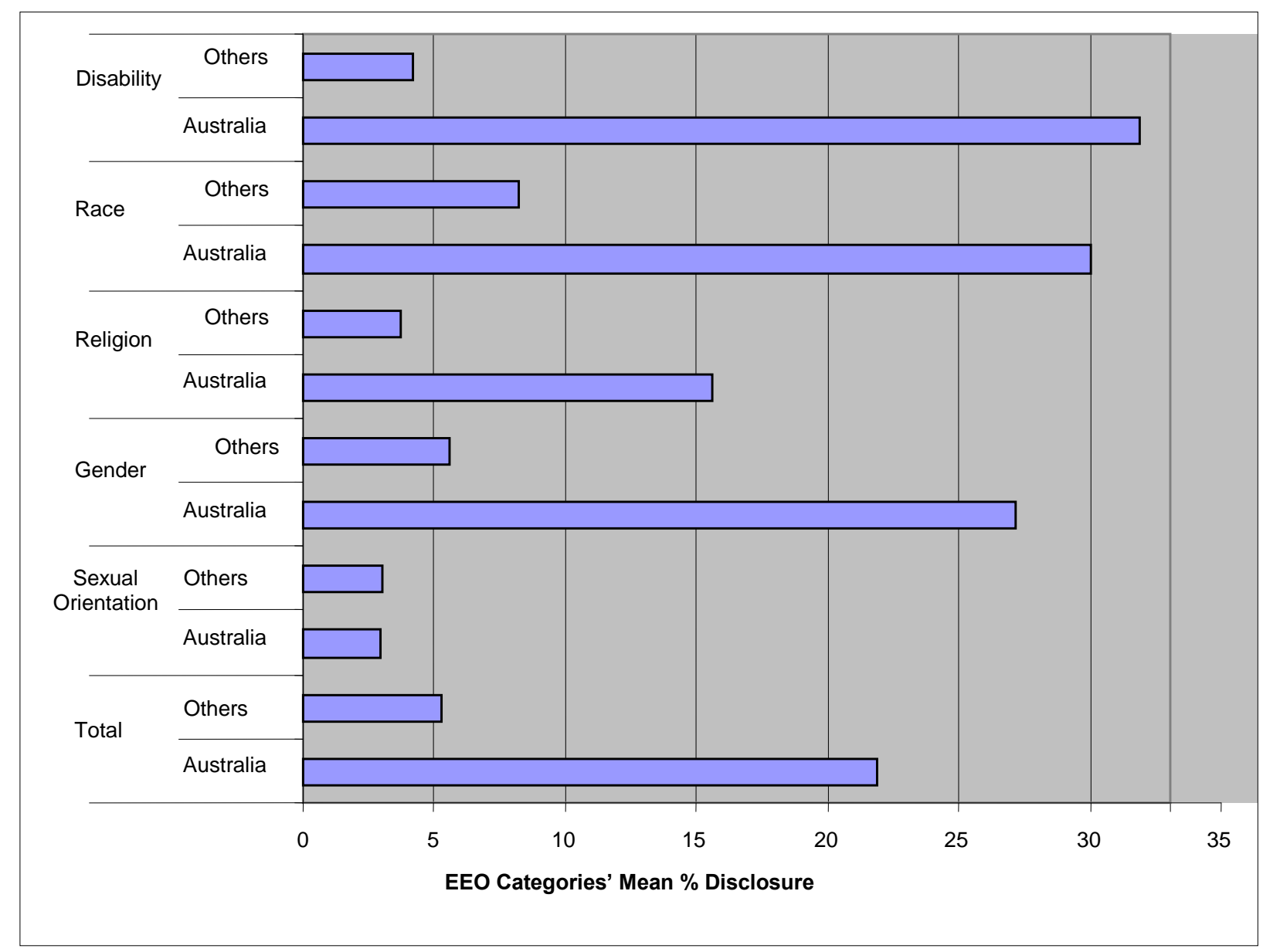

Table 1 further reveals that Australian universities disclose an average of $22 \%$ of these key EEO issues whereas all the other countries' tertiary bodies have only a miniscule 5\% average. T-Test analysis confirms this as a statistically significant difference (p-value 0.04). The Australians also have statistical higher communication levels for 'Gender', 'Race' and 'Disability' sub-categories. Clearly, in the English-speaking countries, they are the clear leaders in EEO communication.

What becomes exceedingly apparent through Figure 1 and Table 1 are the low overall levels of disclosure across all subcategories. The highest disclosure levels are seen in the disability category with Australian institutions demonstrating mean disclosure levels of over $31 \%$. This is in comparison with the mean level of disclosure the 'other' countries institutions displayed of under 5\%. Another major issue that becomes apparent in both Figure 1 and Table 1 is the disclosure of issues relating to sexual orientation. Disclosure in Australian and other institutions from around the world both sit well under the $5 \%$ mean disclosure level.

Additional multiple regression results (not shown for brevity) confirms that the 'Country' variable (Australia versus all other top ranked Anglo-American country universities) is a statistical predictor for all categories except for 'Sexual Orientation'. In this latter category, both country categories have virtually no 
communication of these issues. Other typical explanatory factors found in the extant literature such as size, profit and leverage are not predictors of EEO communication levels for these Anglo-American universities. This is interesting in that unlike many other accounting studies that has examined other industry groups--bigger and better resourced universities are failing to communicate more.

Table 1: Statistical Analysis of EEO Levels: Australia \& Other Anglo-American Countries

\begin{tabular}{|c|c|c|c|c|}
\hline & Country & Mean \% & Std Dev \% & P-value \\
\hline \multirow[t]{2}{*}{ Sexual Orientation \% disclosure } & Australia & 2.92 & 4.86 & \\
\hline & Others & 3.016 & 5.74 & 0.96 \\
\hline \multirow[t]{2}{*}{ Gender \% disclosure } & Australia & 27.17 & 23.56 & \\
\hline & Others & 5.59 & 7.76 & $0.04 * *$ \\
\hline \multirow[t]{2}{*}{ Religion \% disclosure } & Australia & 15.63 & 27.96 & \\
\hline & Others & 3.69 & 8.56 & 0.27 \\
\hline \multirow[t]{2}{*}{ Race \% disclosure } & Australia & 30.00 & 29.03 & \\
\hline & Others & 8.21 & 10.52 & $0.07 * * *$ \\
\hline \multirow[t]{2}{*}{ Disability \% disclosure } & Australia & 31.88 & 25.77 & \\
\hline & Others & 4.17 & 7.40 & $0.02 * *$ \\
\hline \multirow[t]{2}{*}{ Total \% disclosure } & Australia & 21.97 & 18.74 & \\
\hline & Others & 5.25 & 7.15 & $0.04 * *$ \\
\hline
\end{tabular}

\section{EEO STATUS QUO AND FUTURE CRYSTAL BALL GAZING}

Equal Employment and Opportunity practices are arguably very important and should be clearly communicated by major organizations. The top ranked Anglo-American universities exert extensive influence on their societies. Therefore, a high level of transparency regarding their EEO practices could be expected.

Surprisingly, the overall transparency of EEO activities by these global leaders is very low, with over $90 \%$ non-disclosure of key issues. These higher education bodies are 'failing the final exam' for transparency and openness. Their policies are opaque and ambiguous. This is especially true for 'Sexual Orientation' issues wherein one could expect that for such a topic tertiary bodies would be on the cutting edge of liberalism and acceptance. Whilst still not dramatically high, the top Australian universities communicate far more information on many key issues. It is recommended that their more expansive reporting approach should be adopted as the initial template for improved transparency and communication in the higher education community.

\section{ACKNOWLEDGEMENTS}

The authors of this research would like to extend their gratitude for the valuable insights offered by the seminar participants at European Applied Business Research conference in Salzburg, Austria in June 2008.

\section{AUTHOR INFORMATION}

Dr Greg Tower is a professor in the School of Accounting at Curtin University of Technology in Perth Australia. Greg has over 70 refereed journal articles on a wide variety of business communication, organizational performance and comparative international accounting topics. He is especially interested in research that examines innovative ways of improving better understanding of business activities and practices. Greg has successfully supervised over 30 postgraduate research students and has an extensive track record of successful external research grants. He was awarded the 'Researcher of the Year' award in 2007 by the Curtin Business School.

Dr Julie Plummer is an Associate Professor at the University of Western Australia in agricultural science. She has 22 years experience in teaching and research. She has published 127 articles including 69 peer-reviewed papers, 22 in the last 5 years. She has had over $\$ 4$ million in research funding, including $\$ 1.3$ million from Australian government agencies through national competitive grants. Julie has successfully supervised over 50 research 
students. Her excellence in teaching was recognized with the Australian Society for Plant Physiologists National Teaching Award in 2000 and nomination for a UWA Student Guild Postgraduate Supervision Award in 2006.

Emily Goforth conducts research activities in the Curtin Business School, Curtin University of Technology. Her wide-ranging research interests include psychology, decision-making in both personal and business settings, human behavioral patterns, fitness wellbeing and changing societal attitudes.

Brenda Ridgewell lectures at the School of Art at Curtin University of Technology. She explores the creative aspects of art, especially in innovative jewellery design which emphases light, space and form. Her jewellery has been exhibited both nationally and internationally, and acquired by many collectors both public and private including the National Gallery of Australia.

Spence Tower has his Ph.D. from Michigan State University in Organizational Behavior with an emphasis in Human Resource Management. For the previous ten years he had been teaching graduate and undergraduate organizational behavior, strategic management, human resources, and numerous other management classes. He is currently an assistant professor at Ferris State University in Michigan and has also taught in California, Illinois and the University of Pittsburgh's Semester at Sea Program. He has consulted with organizations such as Health Canada, Independent Bank, Aetna, Tenneco, The National Charter School Institute, and the Girl Scouts of America.

\section{REFERENCES}

1. Benschop, Y. and H. Meihuizen, E. 2002. Keeping up gendered appearances: representations of gender in financial annual reports. Accounting, Organizations and Society 27: 611-636.

2. Bernardi, R., A., D. Bean, F. and K. Weippert, M. 2005. Minority membership on boards of directors: the case for requiring of boards in annual reports. Critical Perspectives on Accounting 16: 1019-1033.

3. D'Augelli, A., R. 1989. Lesbian and gay men on campus: Visibility, empowerment and educational leadership. Peabody Journal of Education 66 (3): 124-142.

4. Daly, B., A. 2005. Color and gender based differences in the sources of influence attributed to the choice of college major. Critical Perspectives on Accounting 16: 27-45.

5. Fitzgerald, L., F., S. Shulliman, L., N. Bailey, M. Ormerod, J. Swecker, Y. Gold, M. Richards and L. Weitzman. 1988. The incidence and dimensions of sexual harassment in academia and the workplace. Journal of Vocational Behavior 32: 152-175.

6. Grosser, K. and J. Moon. 2005. Gender mainstreaming and corporate social responsibility: Reporting workplace issue Journal of Business Ethics 62: 327-340.

7. Hammond, T., David. 1997. Sexual harassment and the public accounting industry: The need for critical examination. Critical Perspectives on Accounting 8: 267-271.

8. Jacobs, J., A. 1996. Gender inequality and higher education, Annual Review Sociology 22: 153-185.

9. Kastl, M., A. and B. Kleiner, H. 2001. New developments concerning discrimination and harassment in universities. International Journal of Sociology and Social Policy 21 (8-10): 156-164.

10. Kelley, M., L. and B. Parsons. 2000. Sexual harassment in the 1990s. The Journal of Higher Education 71 (5): 548-568.

11. Kirkham, L. M. 1997. Through the looking glass: Viewing sexual harassment within the accounting profession. Critical Perspectives on Accounting 8: 273-283.

12. Menges, R., J. and W. Exum, H. 1983. Barriers to the progress of women and minority faculty. The Journal of Higher Education 54 (2): 123-144.

13. Nichols, D., R. K. Robinson, B. J. Reitthelt and G. M. Franklin. 1997. An exploratory study of sexual behavior in accounting firms: Do male and female CPAs interpret sexual harassment differently? Critical Perspectives on Accounting 8: 249-264.

14. Sewell, W., H. 1971. Inequality of opportunity for higher education. American Sociological Review 36 (5): 793-809.

15. Stockdale, M., S. and A. Vaux. 1993. What sexual harassment experiences lead respondents to acknowledge being sexually harassed? A secondary analysis of a university survey Journal of Vocational Behavior 43: 221-234. 
16. Suarez-Balcazar, Y., L. Orellana-Damacella, N. Portillo, J. Rowan, M. and C. Andrews-Guillen. 2003. Experiences of differential treatment among college students of color. The Journal of Higher Education 74 (4): 428-444.

17. The Times Higher Education Supplement, 2007. World University Rankings.

18. Todd, P. and D. Bird. 2000. Gender and promotion in academia. Equal Opportunities International 19 (8): $1-16$.

19. Tower, G. Plummer, J. Ridgewell, B., Goforth, E. and Tower, S. (2008a). The World's Best AngloAmerican Universities' Knowledge Management Attributes, European Applied Business Conference, Rothenburg, Germany, 18-20.

20. Tower, G. Plummer, J. Ridgewell, B., Goforth, E. and Tower, S. (2008b). Equity and Diversity in Tertiary Institutions, College and Teaching Conference, Rothenburg, Germany, 18-20.

21. Vuontisjarvi, T. 2006. Corporate social reporting in the European context and human resource disclosures: An analysis of Finnish companies. Journal of Business Ethics 69: 331-354.

22. Weisenfeld, L. and I. Robinson-Backmon. 2001. Minority accountants' views on gender and race biases, career limitations and suggestions for undergraduate educational institutions. Journal of Accounting Education 19: 163-187.

23. Worland, D. and R. Anderson. 1991. Disclosure of human resource information by Australian companies in annual reports. Asia Pacific Journal of Human Resources 21: 21-35. 